\title{
A TaqI map of the dystrophin gene useful for deletion and carrier status analysis
}

\author{
Ann P Walker, Nigel G Laing, Tomoko Yamada, David C Chandler, Byron A Kakulas, \\ Richard J Bartlett
}

\begin{abstract}
We describe a partial TaqI map of the dystrophin gene, obtained mainly by analysis of 87 overlapping DMD/BMD deletions with small fragments of the dystrophin cDNA probes; exon 6 of the dystrophin gene was identified on the TaqI map using the polymerase chain reaction. The cDNA probes detect five polymorphisms with TaqI, more than with HindIII (one), BgII (four), or Pst (three). The five polymorphisms are analysed concomitant with screening for deletions on the TaqI map, and in the onethird of DMD/BMD cases with no detected deletion the polymorphism information may be used for counselling. Correlation of the TaqI map with the HindIII map in the region of probes $5 b-7$ and 8 has allowed the establishment of reading frame. In this region of the dystrophin gene, all of 41 DMD deletions resulted in a shift of reading frame and all of $10 \mathrm{BMD}$ patients maintained reading frame, in agreement with the 'reading frame hypothesis'.
\end{abstract}

Duchenne and Becker muscular dystrophies (DMD/BMD) both arise from mutation of the dystrophin gene on the short arm of the $\mathrm{X}$ chromosome. In most cases, deletions of the dystrophin gene are detected, allowing direct DNA based prenatal and carrier diagnosis. ${ }^{1-3}$ However, in approximately one-third of cases, no mutation is detected and counselling is offered by linkage analysis of polymorphic markers. The entire dystrophin cDNA has been cloned and the HindIII exon containing fragments have been ordered into a partial map. ${ }^{45}$ The normal exon containing restriction fragments and polymorphisms detected by hybridisation with the CDNA probes have been described for HindIII and BglII, and polymorphisms were reported for two additional restriction enzymes, Pst I and TaqI. ${ }^{6}$ In order to facilitate concomitant screening for deletions, duplications, and polymorphisms, we characterised the normal cDNA hybridisation pattern for $T a q I$ and arranged the exon containing fragments into a partial TaqI map.

Correspondence to Dr Walker, Human Genetics Laboratory, ICRF

Laboratories, Institute of Molecular Medicine, John Radcliffe Hospital, Headington, Oxford OX3 9DU.

Reprint requests to Dr Bartlett

Received 25 February 1991 Revised version accepted 5 June 1991.

\section{CLINICAL EVALUATION}

Materials and methods

A total of 128 families (98 DMD and 30 BMD) was examined by neurologists of the MDA clinics at Duke University Medical Center, Durham, NC, USA, and the Australian
Neuromuscular Research Institute, Queen Elizabeth II Medical Centre, Perth, WA, Australia. One additional sample of patient DNA was provided by Dr M J Denton, the Prince of Wales Hospital, Sydney, NSW, Australia. The probands were diagnosed using standard clinical diagnostic criteria for DMD/BMD in conjunction with raised creatine kinase activity and typical dystrophic changes on muscle biopsy. Diagnosis was also confirmed in 14 families by dystrophin analysis (Genica, Inc, Worcester, MA) or immunohistochemistry using antidystrophin antibodies.?

RESTRICTION DIGESTION, SOUTHERN TRANSFER, AND HYBRIDISATION

DNA isolated from whole blood or from lymphoblast cell lines was digested with restriction enzymes TaqI, HindIII, BglII, or Pst I (BRL, Gaithersburg, MD, USA; NEB, Beverly, MA, USA; Toyobo, Kitaku, Osaka, Japan). The resulting DNA fragments were separated by agarose gel electrophoresis, Southern transferred onto GeneScreen Plus membrane (NEN DuPont, Boston, MA), hybridised to an oligolabelled probe, and autoradiographed. These methods have been described in detail previously. ${ }^{189}$

CDNA PROBES

The six probes comprising the $14 \mathrm{~kb}$ dystrophin cDNA were kindly provided by Dr L M Kunkel $^{4}$ or were obtained from ATCC. To order the $T a q I$ exon containing fragments, probes 1-2a, 5b-7, and 9-14 were each divided into smaller probe fragments (fig 1) for

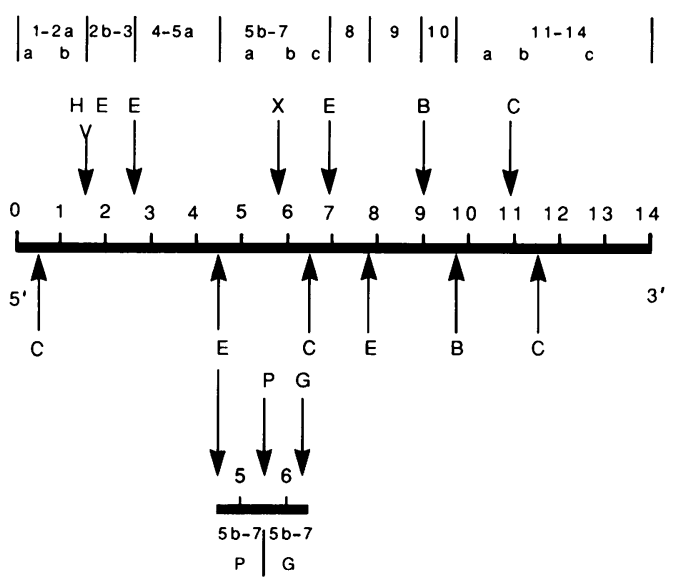

Figure 1 Dystrophin cDNA probe fragments. Restriction enzymes: $B=B a m H I, C=H i n c I I, E=E c o R I, G=B g l I I$, $H=$ Hind III,$P=P$ st $I, X=X b a I$. 


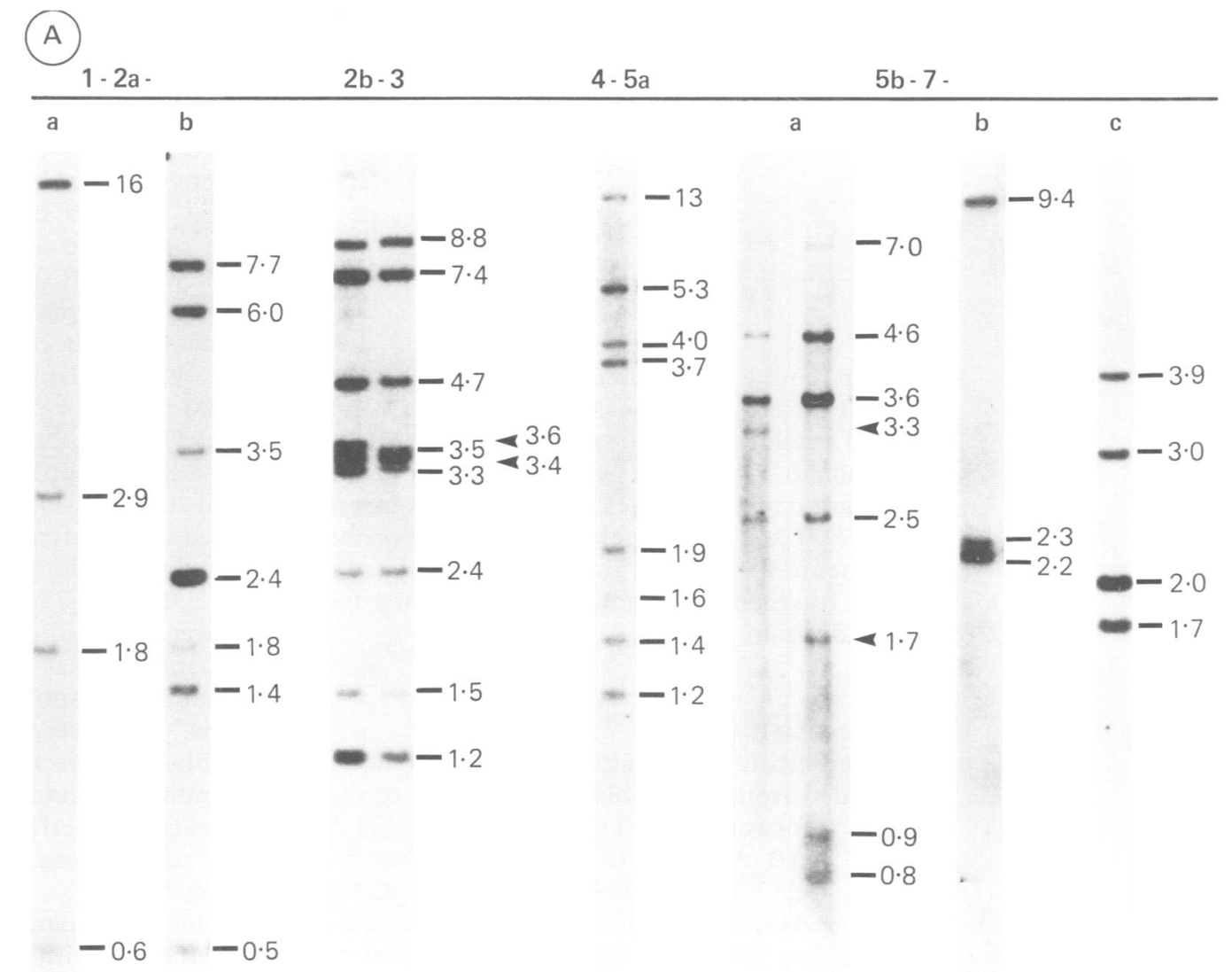

(B)

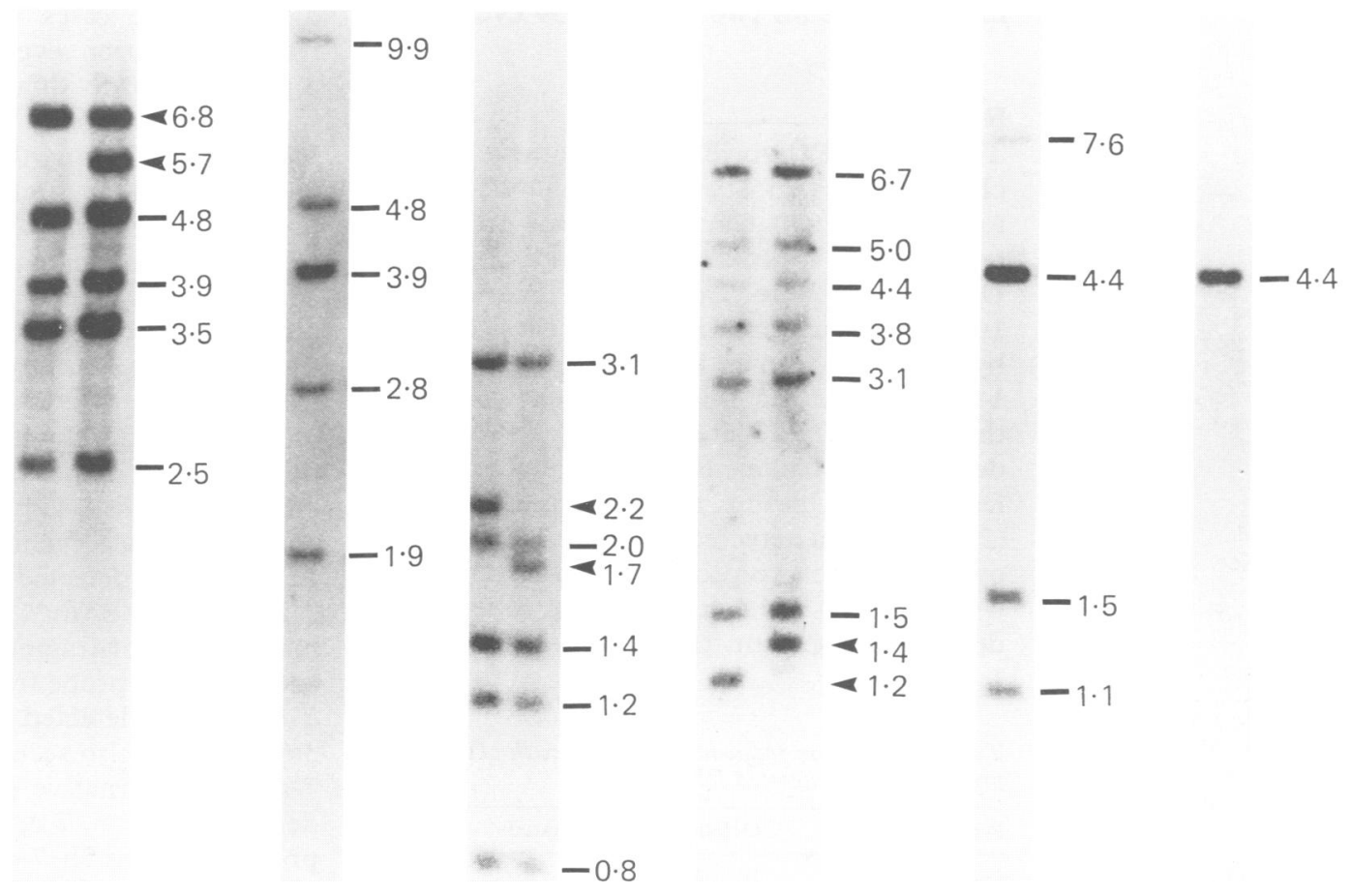

Figure 2 Normal hybridisation pattern of the cDNA probes for TaqI. (A) cDNA probes 1-2a to 5b-7, (B) cDNA probes 8 to 11-14. Constant bands are indicated by horizontal bars; the five polymorphisms are indicated by arrows (sizes in kb). DN $A$ in the left hand lane for probe $2 b-3$ and the right hand lane for probe 8 is from a female; all other lanes contain DNA from males.

hybridisation in some experiments. Probe $5 \mathrm{~b}-$ 7 was used to prepare two different sets of probe fragments, so that the order of TaqI exon containing fragments at the $5^{\prime}$ end of this 
Table 1 TaqI polymorphisms detected with dystrophin cDNA probes.

\begin{tabular}{|c|c|c|c|c|}
\hline \multirow[t]{2}{*}{ Probe } & \multicolumn{2}{|c|}{ Allele size $(\mathbf{k b})$} & \multirow[t]{2}{*}{ Frequency } & \multirow[t]{2}{*}{ No } \\
\hline & \multicolumn{2}{|c|}{ Frequent allele Rare allele } & & \\
\hline $\begin{array}{l}2 b-3 \\
5 b-7-a \\
8 \\
9-14-b \\
9-14-c\end{array}$ & $\begin{array}{l}3.4 \\
3 \cdot 3 \\
6 \cdot 7 \\
1 \cdot 7 \\
1.2\end{array}$ & $\begin{array}{l}3.6 \\
1.7 \\
5.9 \\
2.2 \\
1.4\end{array}$ & $\begin{array}{l}0.54 / 0 \cdot 46 \\
0.52 / 0.48 \\
0.94 / 0.06 \\
0.93 / 0 \cdot 07 \\
0.73 / 0.27\end{array}$ & $\begin{array}{r}112 \\
105 \\
125 \\
106 \\
63\end{array}$ \\
\hline
\end{tabular}

region could be resolved. Digestion of the $E c o$ RI insert of probe $5 \mathrm{~b}-7$ with $X b a I$ and $H$ incII yielded probe fragments $5 \mathrm{~b}-7-\mathrm{a}, 5 \mathrm{~b}-7-$ $b$, and $5 b-7-c$, which were used for routine deletion screening; digestion of the $5 \mathrm{~b}-7$ insert with PstI and BglII yielded alternative probe fragments 5b-7-P and 5b-7-G (fig 1), plus two small fragments $(0.2$ and $0.5 \mathrm{~kb})$ not used for hybridisation.

\section{PCR AMPLIFICATION}

Oligonucleotide primers for exon 6 were designed from the published sequence of the gene $^{10}$ : forward 5'-GTC AAA AAT GTA ATG AAA AAT ATC ATG-3'; reverse 5'TAT GAC TAT GGA TGA GAG CAT TCA AAG-3'. Amplification was performed using Taq DNA polymerase (Biotech International, Bentley, Western Australia) with $5 \mathrm{ng}$ target DNA in a final volume of $25 \mu$ l under the supplier's reaction conditions. The cycle profile was: $94^{\circ} \mathrm{C}$ for three minutes, $55^{\circ} \mathrm{C}$ for one minute, $75^{\circ} \mathrm{C}$ for two minutes (one cycle); $94^{\circ} \mathrm{C}$ for 30 seconds, $55^{\circ} \mathrm{C}$ for one minute, $75^{\circ} \mathrm{C}$ for two minutes (39 cycles).

\section{Results}

The normal hybridisation pattern of the cDNA probes on TaqI digested DNA shows a total of 68 exon containing TaqI fragments, representing approximately $250 \mathrm{~kb}$ of genomic DNA (fig 2). The cDNA probe 1-2a detected $10 \mathrm{Taq}$ I fragments, with four of these detected by $1-2 a-a$ and seven by $1-2 a-b$. Both parts of $1-2 \mathrm{a}$ detected the $1.8 \mathrm{~kb}$ fragment containing the cDNA HincII site of exon $4 .{ }^{10}$ Probe $2 b-3$ detected a two allele RFLP and eight constant fragments. One of the constant fragments $(2.4 \mathrm{~kb})$ is also detected by probe $1-2 \mathrm{a}$ owing to overlap of the two probes in exon $11 .^{610}$ Probe 4-5a detects eight fragments. Probe 5b-7-a detects six constant fragments and a two allele

Table 2 Deletion frequencies detected with cDNA probes on TaqI digested DNA.

\begin{tabular}{llr}
\hline Probe & Deletions/families tested & $\%$ \\
\hline $1-2 \mathrm{a}$ & $18 / 133$ & 14 \\
$2 \mathrm{~b}-3$ & $19 / 136$ & 14 \\
$4-5 \mathrm{a}$ & $10 / 127$ & 8 \\
$5 \mathrm{~b}-7-\mathrm{a}$ & $5 / 115^{*}$ & 4 \\
$5 \mathrm{~b}-7-\mathrm{b}$ & $4 / 135$ & 3 \\
$5 \mathrm{~b}-7-\mathrm{c}$ & $42 / 133$ & 32 \\
8 & $57 / 140^{*}$ & 41 \\
9 & $7 / 117$ & 6 \\
10 & $1 / 107$ & 1 \\
$11-14-\mathrm{a}$ & $0 / 63$ & 0 \\
$11-14-\mathrm{b}$ & $0 / 52$ & 0 \\
$11-14-\mathrm{c}$ & $0 / 56$ & 0 \\
\hline
\end{tabular}

* One probable duplication also detected (see Results).
RFLP. Probes 5b-7-b and 5b-7-c detect three and four fragments, respectively. Probe $8 \mathrm{de}-$ tects a two allele RFLP and four constant fragments, one of which $(3.9 \mathrm{~kb})$ is also detected by $5 b-7-c$. A common fragment is also detected by these two probes on HindIII digests. ${ }^{6}$ Probe 9 detects five constant fragments; probes 10 and 11-14-a both detect a two allele RFLP, as well as five and eight constant fragments, respectively. Probe 1114-b detects four constant fragments; one of these $(4.4 \mathrm{~kb})$ is also the only fragment detected by $11-14-c$.

The cDNA probes $2 b-3,5 b-7-a, 8,10$, and 11-14-a each identified a TaqI RFLP, making a total of five cDNA RFLPs which are detected with this enzyme, spanning the length of the dystrophin gene ${ }^{61112}$ (table 1). When intact cDNA $5 \mathrm{~b}-7$ is hybridised to TaqI blots, the lower $1.7 \mathrm{~kb}$ allele comigrates with a constant band, so that densitometric scanning of the autoradiograph is necessary for RFLP analysis. ${ }^{6}$ However, the smaller cDNA fragment $5 \mathrm{~b}-7-\mathrm{a}$ detects the RFLP but not the comigrating constant fragment, so that RFLP analysis can be performed directly (fig 2 ). The $1.7 \mathrm{~kb}$ constant band is detected by probe segment $5 \mathrm{~b}-7-\mathrm{c}$.

A total of 128 patients (98 DMD, $30 \mathrm{BMD}$ ) was screened with the cDNA probes, and deletions were observed in $72 \%(71 / 98)$ of DMD cases and 53\% (16/30) of BMD cases, for an overall deletion frequency of $68 \%$. In two of the DMD cases, all exon containing bands were detected, plus an additional junction fragment, seen both on TaqI and BglII digests; these cases were presumed to arise from duplication events. TaqI and HindIII digests of individual DNA samples were screened sequentially with the entire cDNA in most cases, allowing the extent of any deletion to be determined. Deletions in different families were compared, and regions of overlap were used to determine the order of TaqI exon containing fragments (fig 3). The TaqI fragment corresponding to exon 6 was identified by hybridising radiolabelled reaction product from a PCR reaction to a TaqI digest previously hybridised with cDNA 1-2a. This was done since no patients were deleted solely for either the 7.7 or $1.4 \mathrm{~kb}$ bands, now identified as corresponding to exons 6 and 7, respectively. In the region detected by probe fragments $5 \mathrm{~b}$ 7-a and 5b-7-b (fig 1), only one deletion was informative for fragment order. Hybridisation of alternative probe fragment $5 \mathrm{~b}-7-\mathrm{P}$ (fig 1 ) to TaqI digests detected the $4 \cdot 6,2 \cdot 5,0.9,0 \cdot 8$, and $3.6 \mathrm{~kb}$ bands also seen by probe fragment $5 \mathrm{~b}$ 7-a. The alternative probe fragment 5b-7-G detected the $3.6,7 \cdot 0$, and $3 \cdot 3 / 1 \cdot 7 \mathrm{~kb}$ bands of probe fragment $5 \mathrm{~b}-7-\mathrm{a}$, plus the 9.4 and $2 \cdot 2 \mathrm{~kb}$ bands of probe fragment $5 b-7-b$. Combining information derived from the informative deletion and from hybridisation with the two sets of probe fragments, the order of TaqI fragments at the $5^{\prime}$ end of $5 \mathrm{~b}-7$ could be determined (fig 3 ). In the region detected by probes $5 \mathrm{~b}-7-\mathrm{c}$ and 8 , which is the region of most frequent deletion, each exon containing TaqI restriction fragment was correlated with the 


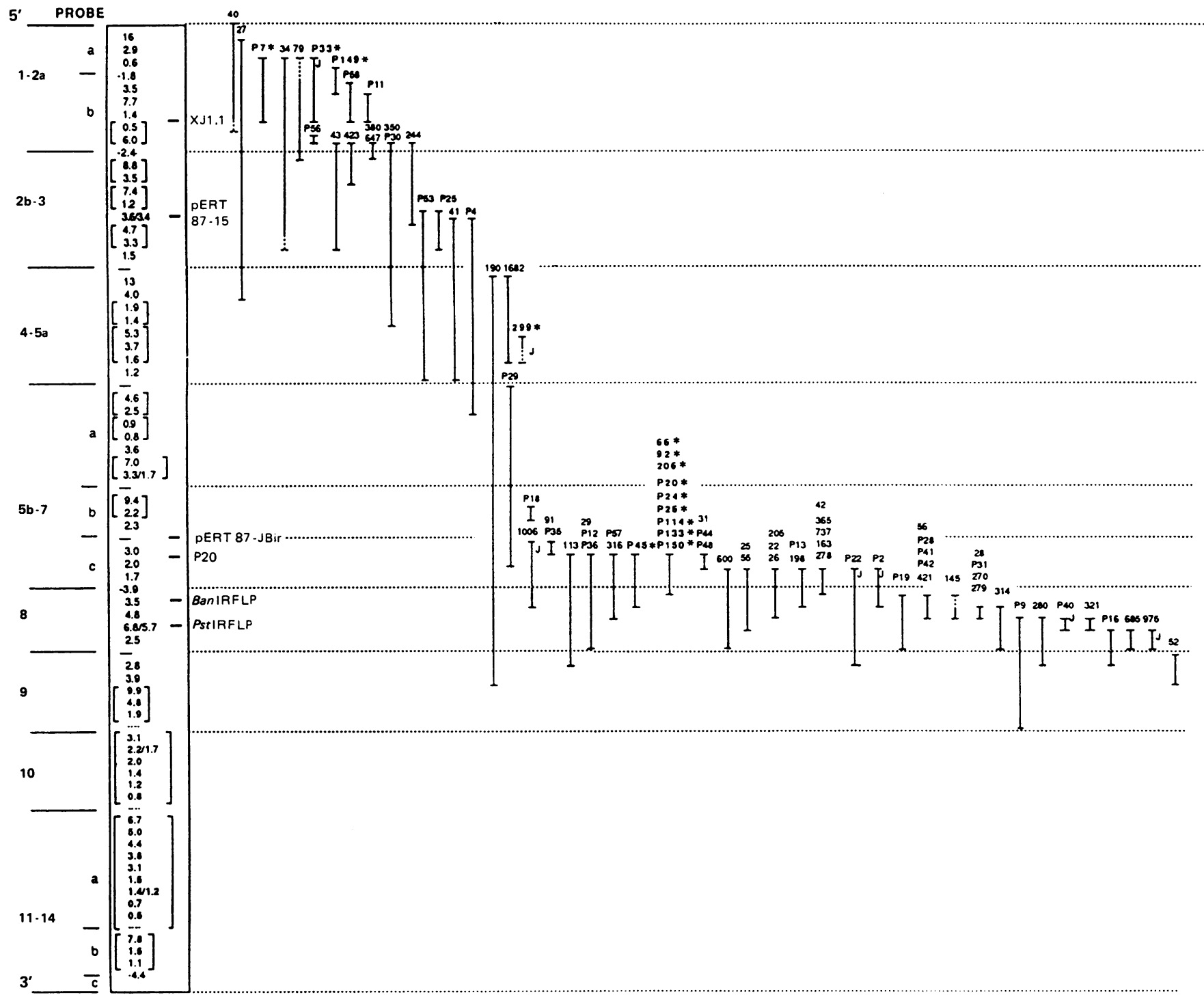

Figure 3 A TaqI map of exon containing fragments of the Duchenne muscular dystrophy gene. The cDNA probes are shown in the left hand column. Exon containing fragments hybridising to each probe are shown in the box, in the most likely order (sizes in kb). Brackets indicate bands for which the order has not yet been determined. The positions of genomic probes Xf1.1, pERT87-15, ҰBir, and P20, and the exon containing for which the order has not yet been determined. The positions of genomic probes $\mathrm{X}$ mich detect BanI and Pst polymorphisms, are indicated on the TaqI map. Vars show the extent of TaqI deletions detected in $83 D M D / B M D$ families. Solid bars denote definite deletions; dashed bars denote the possible maximum extent of deletion for faintly hybridising bands difficult to score accurately. Family numbers are given above each deletion. ${ }^{*}$ denotes $B M D$ families. $\mathcal{f}=$ junction fragment.

corresponding fragment of the HindIII map. ${ }^{4513}$ The fragment order for TaqI was consistent with that for HindIII in all cases tested. This allowed the exon border type of deletions in this region to be established. ${ }^{14}$ In all $41 \mathrm{DMD}$ and $10 \mathrm{BMD}$ cases tested, DMD patients had deletions which are predicted to cause a frameshift in the translational reading frame, while BMD patients had deletions which are predicted to maintain the reading frame (fig 4). Additional screening with intragenic genomic probes was performed, and XJ1.1, pERT87-15, pERT87-JBir, and P20 were located on the TaqI map. The TaqI RFLP detected by genomic probe pERT87-15 was found to be identical to that detected by cDNA 2b-3 (fig 5).

\section{Discussion}

Deletion screening on TaqI digested DNA allows for concurrent analysis of five RFLPs, so in those families with no detected deletion or duplication counselling by conventional linkage analysis may be facilitated. The TaqI and $H$ indIII maps were correlated over nine exons detected by cDNA probes $5 \mathrm{~b}-7$ and 8 . Although absolute confirmation of order would require sequencing of the $T a q I$ exon containing fragments to ensure that no small fragments had been omitted, in all 51 cases tested in this region the deduced order of exon containing fragments for TaqI and the HindIII order ${ }^{4}$ were consistent.

Similar deletions were observed in DMD and BMD patients, although in no case were the same exon containing fragments deleted in a DMD and a BMD family (figs 3 and 4). The 'reading frame hypothesis' ${ }^{14}$ predicted that frameshift deletions result in production of a truncated, unstable dystrophin protein, leading to severe phenotypes, while deletions that maintain the reading frame result in production of an internally deleted dystrophin protein that is partially functional, leading to mild phenotypes. Testing in a number of different 


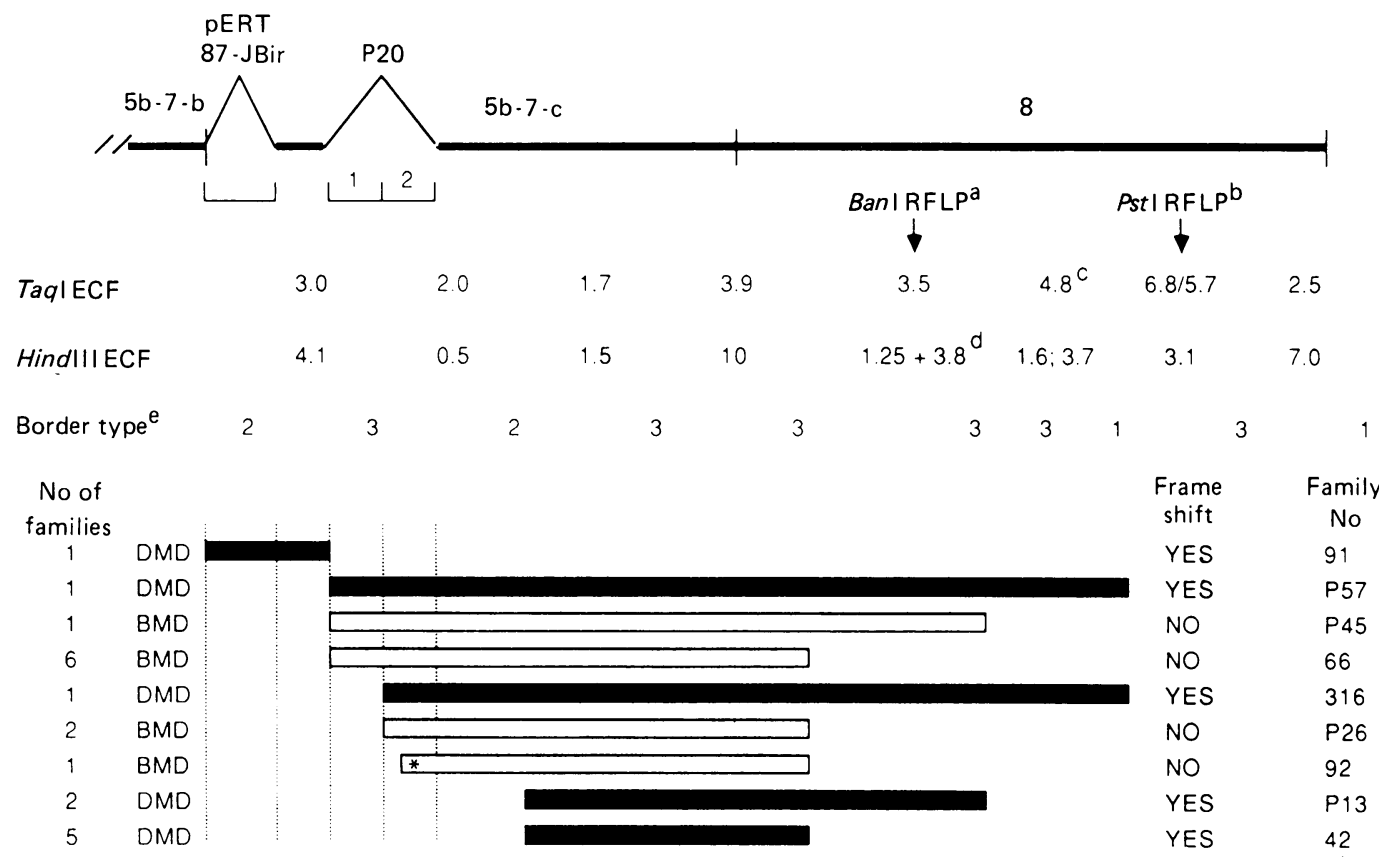

Figure 4 Correlation of TaqI and HindIII maps in the region of frequent deletion. The TaqI and corresponding HindIII exon containing fragments (ECF) are indicated for probes $5 b-7-c$ and 8 (sizes in kb). The positions of genomic probes $\mathcal{F}$ Bir and P20, and of the BanI and PstI cDNA RFLPs for probe 8 are indicated. P20 bands 1 and 2 are the $0.8 \mathrm{~kb}$ and $6.7 \mathrm{~kb}$ TaqI fragments detected with this probe, respectively. ${ }^{15}$ The border type number indicates the relative position of the intron/exon border with respect to the translational reading frame. A border of ' 3 ' denotes an exon/intron border occurring between intact codons of the $m R N A$ (after codon position 3). Borders of ' 1 ' and ' 2 ' denote a border occurring after the first or second nucleotide of the codon, respectively. ${ }^{13}$ The predicted effect that a deletion would have upon frameshift of dystrophin $m R N A$ is indicated. The extent of deletions in 10 BMD cases (open bars) and $10 \mathrm{DMD}$ cases (solid bars) is indicated. An asterisk indicates a TaqI junction fragment detected with P20. To the right of the deletion is the family number; to the left is the total number of families observed with that deletion. (a) from reference 16; (b) one TaqI fragment contains two HindIII fragments; (c) two HindIII fragments contain a single exon ${ }^{17}$; $(d, e)$ from reference 13.

patient populations has shown that in the majority of cases the predictions of disease severity based on the expected effects of deletion on dystrophin translation are correct; however, a few exceptions have been observed, particularly at the $5^{\prime}$ end of the gene. ${ }^{1318-20}$ In the frequent deletion region of probes $5 \mathrm{~b}-7$ and 8 that we tested, all BMD patients had deletions that preserved the translational reading frame downstream to the deletion; all DMD patients had deletions that resulted in frameshift (fig 4). In the present study, deletion of the $4.1 \mathrm{~kb}$ HindIII exon containing fragment in family 91 produced a DMD phenotype. Baumbach et $a l^{19}$ reported that this same exon deletion could result in either a DMD or an 'intermediate' DMD/BMD phenotype, so that the predicted effects of exon deletions on transcriptional reading frame do not always allow accurate prognosis of disease severity.

Four genomic probes have been localised on the TaqI map, and permit more precise delineation of deletions. Genomic probe pERT87-15 was found to detect the same polymorphic exon containing TaqI fragment that is detected by the cDNA probe $2 b-3$. Fig 5 shows the use of cDNA $2 b-3$ in a DMD family for screening of deletions and polymorphisms concurrently.

Division of the cDNA to yield 15 probe segments ordered the TaqI exon containing fragments into 15 groups. For routine deletion screening, however, it was not necessary to divide probe $1-2 \mathrm{a}$, as all the bands were well separated; the alternative probe fragments $5 \mathrm{~b}-$ 7-P and 5b-7-G were also not needed for routine screening. Fig 3 shows the distribution of deletions detected, with a central high frequency deletion region and a secondary region of frequent deletion towards the $5^{\prime}$ end. The overall frequency of deletions observed was $68 \%$. No deletions were observed to extend $3^{\prime}$ to cDNA 10 in our data set. Probes $1-2 \mathrm{a}, 2 \mathrm{~b}-3$, $5 b-7-c$, and 8 together detected 83 of $87(95 \%)$ of all deletions in our data set, suggesting that these probes should be used in initial screening for deletions.

In conclusion, a partial TaqI map of exon containing fragments of the dystrophin gene is described, allowing concurrent detection of deletions/duplications and analysis of five polymorphisms. Genomic probes have been localised on the TaqI map, improving resolution of deletion detection. Oligonucleotide primers are described for the amplification of exon 6, allowing its identification on the TaqI map, so that fragments 6 and 7 could be ordered. The TaqI map has been correlated with the HindIII map in the high deletion frequency region of probes $5 b-7-c$ and 8 ; all 51 deletion families screened in this region conformed with the 'reading frame hypothesis'. Although multiplex polymerase chain reaction (PCR) will probably be increasingly used for initial deletion screening, owing to the rapidity 


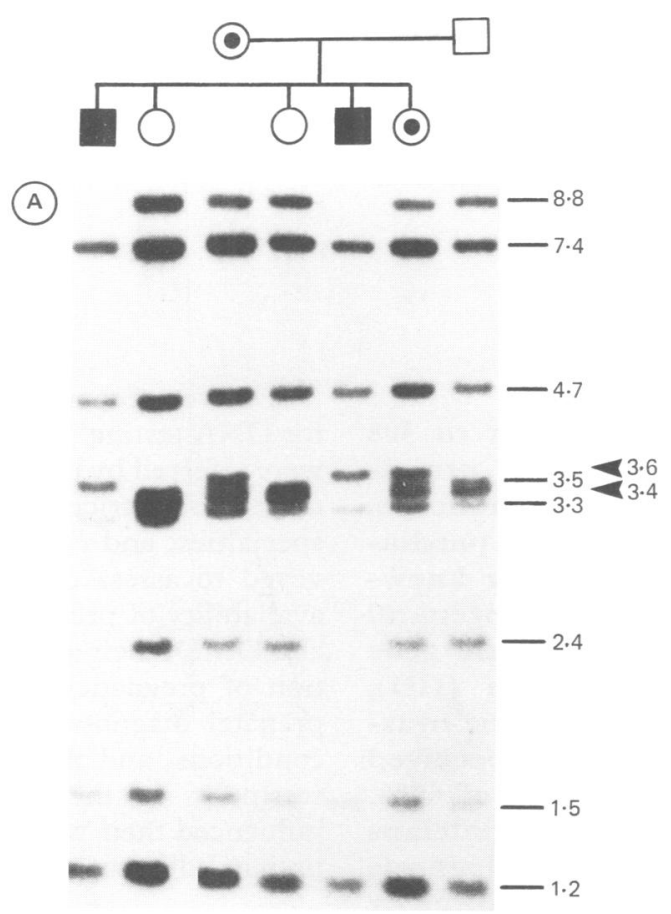

(B)

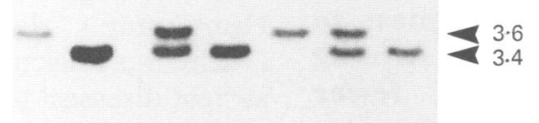

Figure 5 Concurrent screening for deletions and polymorphisms on the TaqI map. (A) cDNA probe $2 b-3$ hybridised to TaqI digests of DMD family 423 $D N A$. Arrows indicate the polymorphic fragments at 3.6 and $3.4 \mathrm{~kb}$. In this family, deletion involves the fragments at 8.8, 3.5, and $2.4 \mathrm{~kb}$. (B) After stripwashing and autoradiography to verify removal of probe, the same blot was hybridised with the genomic probe pERT87-15. The position and inheritance of the alleles was identical to those of the $2 b-3$ RFLP, indicating that genomic probe $p E R T 87-15$ hybridises to the same exon containing fragment which shows $a$ polymorphism in $2 b-3$, thus locating this genomic probe on the TaqI map.

of the process, ${ }^{17}$ primers for all exons have not yet been identified and characterised. Southern hybridisation allows conventional linkage analysis to be used in those families with no detected deletion, and will remain an important analytical tool until better techniques are developed for identification of putative microdeletions and point mutations in the more than $2 \mathrm{Mb}$ of the dystrophin gene.

We thank L M Kunkel, G J B van Ommen, M C Wapenaar, and R G Worton for probes and antibodies; $M$ J Denton for DNA sample 1682; S L Secore, P A Akkari, M G Layton, $M$ E Mears, L $H$ Yamaoka, and W-Y Hung for technical assistance; M C Speer, M A Pericak-
Vance, and J M Stajich for family ascertainment; T Siddique for family 423 DNA; and F Mechler and A D Roses for helpful discussion. This study was supported by clinical research grants (RJB) and a postdoctoral fellowship (APW) from the MDA (America), research grant from the AFM-France (RJB), the Australian National Health and Medical Research Council, and the Appealathon and Neuromuscular Research Foundations of Western Australia (NGL, BAK).

1 Bartlett RJ, Pericak-Vance MA, Koh J, et al. Duchenne muscular dystrophy: high frequency of deletions. Neuro$\log y$ 1988;38:1-4.

2 Speer MC, Pericak-Vance MA, Yamaoka LH, et al. Prenatal diagnosis using deletion studies in Duchenne muscular dystrophy. Prenat Diagn 1988;8:427-37.

3 Laing NG, Siddique T, Bartlett R, et al. Duchenne muscular dystrophy: detection of deletion carriers by spectrophotometric densitometry. Clin Genet 1989;35:393-8.

4 Koenig M, Hoffman EP, Bertelson CJ, Monaco AP, Feener C, Kunkel LM. Complete cloning of the Duchenne muscular dystrophy (DMD) cDNA and preliminary muscular dystrophy (DMD) CDNA and preliminary affected individuals. Cell 1987;50:509-17.

5 Den Dunnen JT, Grootscholten PM, Bakker E, et al. Topography of the Duchenne muscular dystrophy gene: FIGE and CDNA analysis of 194 cases reveals 115 deletions and 13 duplications. Am $\mathcal{F}$ Hum Genet 1989;45:83547

6 Darras BT, Francke U. Normal human genomic restriction-fragment patterns and polymorphisms revealed by hybridization with the entire dystrophin cDNA. Am 7 Hum Genet 1988;43:612-9.

7 Hoffman EP, Brown RH, Kunkel LM. Dystrophin: the protein product of the Duchenne muscular dystrophy locus. Cell 1987;51:919-28.

8 Pericak-Vance MA, Yamaoka LH, Haynes CS, et al. Linkage studies in familial Alzheimer's disease, application of the affected pedigree member (APM) method of linkage analysis. Exp Neurol 1988;102:271-9.

9 Yamaoka LH, Pericak-Vance MA, Speer MC, et al. Tight linkage of creatine kinase (CKMM) to myotonic dyslinkage of creatine kinase (CKMM) to myotonic dys-

10 Koenig M, Monaco AP, Kunkel LM. 'The complete sequence of dystrophin predicts a rod-shaped cytoskeletal
quen protein. Cell 1988;53:219-28.

11 Laing NG, Siddique T, Bartlett RJ, et al. RFLP for Duchenne muscular dystrophy cDNA clone 44-1. Nucleic Acids Res 1988;16:7209.

12 Walker AP, Bartlett RJ, Laing NG, et al. RFLP for Duchenne muscular dystrophy cDNA clone 30-2. Nucleic Acids Res 1988;16:9072.

13 Koenig M, Beggs AH, Moyer M, et al. The molecular basis for Duchenne versus Becker muscular dystrophy: correlation of severity with type of deletion. Am $\mathcal{f}$ Hum Genet 1989;45:498-506.

14 Monaco AP, Bertelson CJ, Liechti-Gallati S, Moser $H$, Kunkel LM. An explanation for the phenotypic differences between patients bearing partial deletions of the ferences between patients bearing part

15 Laing NG, Walker AP, Akkari PA, et al. Identification of Duchenne muscular dystrophy genomic probe P20 constant Taq I fragment corresponding to the EcoR V and Msp I polymorphisms. Prenat Diagn 1991;11:63-7.

16 Laing NG, Akkari PA, Chandler DC, et al. Duchenne muscular dystrophy (DMD) gene cDNA 8 Pst I and Taq I polymorphisms involve exon 51 of the Hind III map. Nucleic Acids Res 1990;18:4284.

17 Chamberlain JS, Gibbs RA, Ranier JE, Nguyen PN, Caskey CT. Deletion screening of the Duchenne muscular dystrophy locus via multiplex DNA amplification. Nucleic Acids Res 1988;16:11141-56.

18 Malhotra SB, Hart KA, Klamut HJ, et al. Frame-shift deletions in patients with Duchenne and Becker muscular dystrophy. Science 1988;242:755-9.

19 Baumbach LL, Chamberlain JS, Ward PA, Farwell NJ Caskey CT. Molecular and clinical correlations of deletions leading to Duchenne and Becker muscular dystrophies. Neurology 1989;39:465-74.

20 Gillard EF, Chamberlain JS, Murphy EG, et al. Molecular and phenotypic analysis of patients with deletions within the deletion-rich region of the Duchenne muscular dystrophy (DMD) gene. Am ₹ Hum Genet 1989;45:507-20. 